\title{
Correction to: Color stability of different composite resins after polishing
}

\author{
Stefano Ardu' ${ }^{1}$ O. Duc ${ }^{2} \cdot$ E. Di Bella ${ }^{3} \cdot$ I. Krejci ${ }^{2} \cdot$ René Daher $^{4}$
}

Published online: 22 February 2018

(c) The Society of The Nippon Dental University 2018

\section{Correction to: Odontology \\ https://doi.org/10.1007/s10266-017-0337-y}

The original article was corrected.

In the original publication of the article, the author's name "Prof. René Daher" was inadvertently missed in the author group. This has been updated in this erratum.

The original article can be found online at https://doi.org/10.1007/ s10266-017-0337-y.

Stefano Ardu

stefano.ardu@unige.ch

1 Treatment Plan Unit and Division of Cariology and Endodontology, Clinique Universitaire de Médecine Dentaire (CUMD), University of Geneva, Rue Barthelemy-Menn 19, 1205 Geneva, Switzerland

2 Division of Cariology and Endodontology, Clinique Universitaire de Médecine Dentaire (CUMD), University of Geneva, Geneva, Switzerland

3 Department of Economics and Business Studies, University of Genoa, Genoa, Italy

4 Teaching and Research Assistant, Division of Cariology and Endodontology, Clinique Universitaire de Médecine Dentaire (CUMD), University of Geneva, Geneva, Italy 